\title{
MANUFACTURE OF SOLAR CELLS ON THE MOON
}

\author{
Alex Freundlich', Alex Ignatiev', Charles Horton', Mike Duke ${ }^{2}$, Peter Curreri', Laurent Sibille \\ 'University of Houston, Houston, Texas, USA, \\ ${ }^{2}$ Colorado School of Mines, Golden, Colorado, USA \\ 3 NASA-Marshall Space Flight Center, Huntsville, Alabama, USA \\ BAE Systems, Huntsville, Alabama, USA
}

\begin{abstract}
In support of the space exploration initiative a new architecture for the production of solar cells on the lunar surface is devised. The paper discusses experimental data on the fabrication and properties of lunar glass substrates, evaporated lunar regolith thin films (antireflect coatings and insulators). and preliminary attempts in the fabrication of thin film (silicon/I-VI) photovoltaic materials on lunar regolith substrates. A conceptual design for a solar powered robotic rover capable of tabricating solar cells directly on the lunar surface is provided. Technical challenges in the development of such a facility and strategies to alleviate perceived difficulies are discussed. Finally, pretininary cost benefit ratio anahysis for different in situ solar cell production scenarios (using exclusively in-situ planetary resources or hybrid) are discussed.
\end{abstract}

\section{WTRODUCTION}

The availability of significant electric power at the surface of the moon will be a principal driver defining the complexity of a lunar base. [1] Proposals to generate power on the moon include both nuclear and solar (photovoltaic) systems. The main drawback to all of the approaches to date is that all of the mass for the power system must be transported from the earth to the moon. For the lunar base this could amount to over 40 metric tons to the moon for the utilization phase.

A more efficient (and possibly synergistic) approach is to attempt to utilize the existing lunar resources to generate the power systems. The synergism occurs from the fact that there is an ultra-high vacuum environment on the surface of the moon, and there are materials present on the moon from which thin film solar cells could be made within this vacuum emvironment by direct evaporation.

Lunar resource utilization has focused principally on the extraction of oxygen from the lunar regolith. A number of schemes have been proposed for oxygen extraction from llmenite and Anorthite. These schemes have as their by-products (or more directly as their "waste products"), materials such as silicon, and aluminum, and these materials are those specifically needed for the fabrication of thin film silicon solar cells.

Thus lunar surface possesses both the elemental components needed for the fabrication of silicon solar cells and a vacuum environment1 (on the order of $10^{-10}$ Torr) that allows for vacuum deposition of thin film solar cells directly on the surface of the Moon without the need for vacuum chambers.

In this paper a new architecture for the in-situ production of solar cells using lunar resources is discussed.

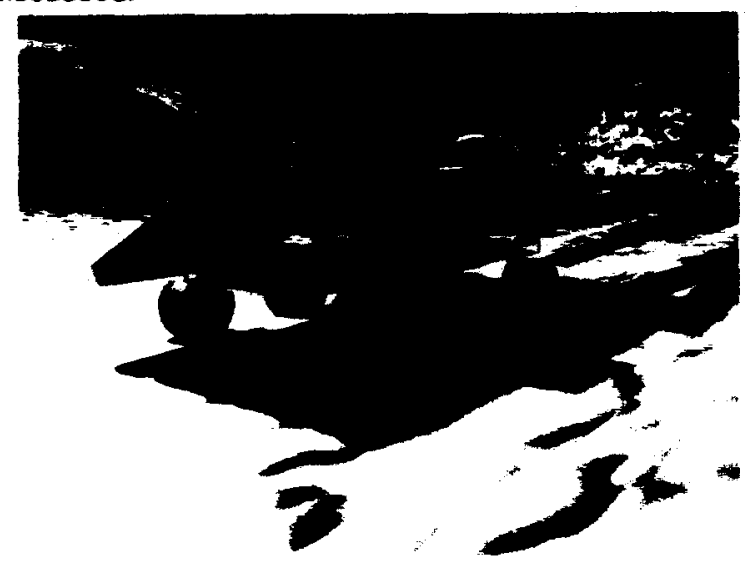

Fig.1. Artist view of a mobile solar cell fabrication facility fabricating solar cells directly on the lunar surface.

\section{RESULTS AND DISCUSSIONS}

\section{Lunar Regolith Substrate Fabrication}

A key component in the concept of in-situ power manufacturing is the development of an electrically isolating and mechanically compatible support structure for the solar cells using lunar resources. By fabricating the support structure on the Moon, the extra mass and 
complexity that must be added to a terrestrial suppont structure for it to survive the launch and transpont is eliminated. The lunar-made substrate (support structure) can be much simpler in that it only needs to support the thin film solar cell. The solar cells would be deposited on this substrate. The substrate needs to be electrically insulating 50 that individual solar cells can be made and then connected in series or parallel circuits to provide an array with useable voltage and current. The surface will need to have features less than the dimensions of the thin film solar cell thickness otherwise a continuous film will not be deposited. The composition of the hunar regolith consists of a variety of oxides that when melted form a glassy solid. We have investigated the melting of the lunar regolith simulant JSC-1 to determine if the glass produced would be suitable as a substrate for lunar solar cells. JSC-1 is similar to typical lunar mare soil with a composition of almost half siticon oxide with the aluminum oxide, calcium oxide, iron oxide and magnesium oxide comprising the majority of the balance. $1^{\prime} \times 1$ ' boats made of tungsten were resistively heated and monitored in a vacuum chamber to melt the regolith samples. The boats were fitted with a type $C$ thermocouple and the temperatures recorded as the regolith was heated. With a uniform fill of regolith in the boat, the material next to the boat at the bottom would melt but the material on the surface away from the edges would not. The regolith is a fine gray powder with low thermal conductivity and a high emissivity. As the regolith is heated, it starts to soften around $1300^{\circ} \mathrm{C}$. The melt is very viscous and evolving gas bubbles out in a thick, lava like fashion. By $1600^{\circ} \mathrm{C}$ the regolith has completely metted and the viscosity is low. The sample is then cooled. The temperature falls quickly (1-2 minutes) to around $300^{\circ} \mathrm{C}$ and then falls stowty after that.

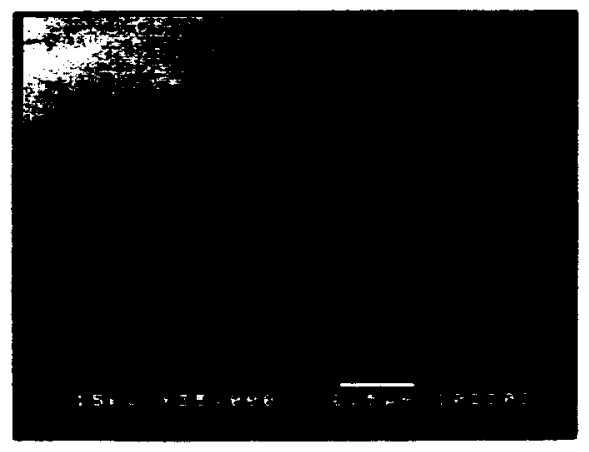

Fig. 2 SEM micrograph of melted lunar regolith surface.

\section{Lunar glass substrate electrical and optical properties and suitebility for PV}

The resistivity of the melted regolith glass substrates was found to exceed $10^{6} \Omega$ - $\mathrm{cm}$. The regolith glass charged quickly under electron bombardment during the Scanning Electron Microscope (SEM) pictures. The free melt surface was found to be very smooth with no features larger than $50 \mathrm{~nm}$ (see Fig. 2.).
During the melting of the regolith, we also found that the regolith could be deposited onto substrates to form thin films. The initial deposition of regolith layers of 1000 $5,000 \AA$ on a coming glass substrate resulted in a film that was so transparent that it was difficult to see on the glass slide. Transmission spectra were taken and the index of refraction was extracted. The index of refraction varied from 1.4 to 1.8 for different regolith thin films. Auger Electron Spectroscopy (AES) was taken to determine the chemical composition the regolith thin film. The film was mostly silicon oxide with a small amount of iron oxide. The optical and electrical properties of the regolith thin film opens up possible uses as anti-reflection coatings and in-situ fabrication of electronic circuits.

In an attempt to evaluate the suitability of the glass substrate made from lunar simulant thin film of CdS and CoTTe were simultaneously deposited on crystalline InP, Corning glass as well as lunar glass substrates. Comparison of optical properties (transmission and photoluminescence (PL) spectroscopy) indicated that films fabricated on lunar regolith glass were even superior in quality than those deposited on commercially available high grade glass and comparable to those observed for films deposited on crystalline InP substrates (Fig. 3).

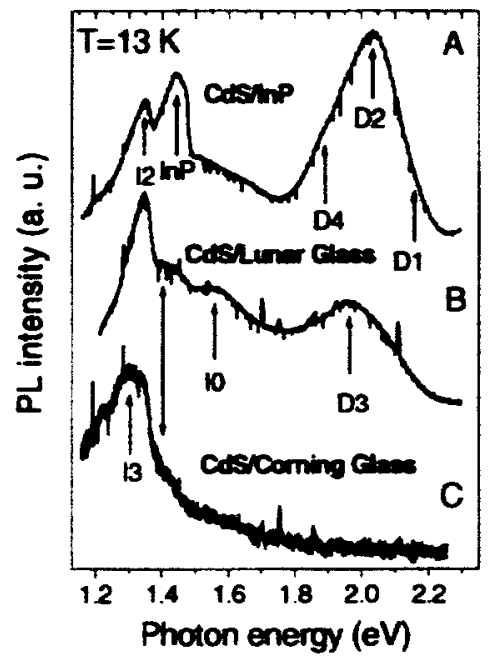

Fig. 3 PL spectra obtained at $T=13 \mathrm{~K}$ for A) CdS on InP. B) CdS on regolith and C) ColS on glass. All samples are from the same evaporation run.

\section{Lunar solar cell manufacturing Facility}

The proposed lunar solar cell manutacturing is comprised of a robotic facility, the "Extractor/Refiner". capable of refining and extracting metals from the lunar ore and a mobile robotic facility, the "Cell Paver", that melts directly the lunar surface to create a glassy substrate and produces directly and integrated solar celltransmission grid on the lunar surface. 
The Cell Paver (Fig. 1) fabricates thin film solar cells and integrates them into a 'panel' strings'/arrays for connection into a solar power system. The Paver is a self-contained, self-reliant mobile fabricator that clears or circumvents rocks and boulders, and smoothes the terrain in front of it. This prepares the site for the fabrication of the lunar glass substrate and subsequent fabrication of the solar cells. Path selection takes into account terrain and obstacle shadowing projected over the full-lighting cycle to preclude shadowing of the array and to maximize power production. The system also uses solar electric energy for motive power command and control. Solar thermal heating is utilized to prepare regolith for substrate and the thermally evaporation of components of the solar cell. Small parabolic collectors generate the $1300{ }^{\circ} \mathrm{C}$ to $1500^{\circ} \mathrm{C}$ needed for the solar cell fabrication, and are integrated with high efficiency light pipes (bundle of optical fibers) to focus/redirect the concentrated solar energy onto the regolith for melting and onto socially dosignod evaporation ovens for silicon and metal deposition (figs. 4). The fiber optic bundle is lined up into 2 to 4 rows to make a line of concentrated solar flux. The solar energy is incident on an emitter plate. The plate will actually heat the regolith. This configuration is used so that any material that is outgassed from the regolith while it is liquid will not coat the end of the fibers and reduce the optical flux.

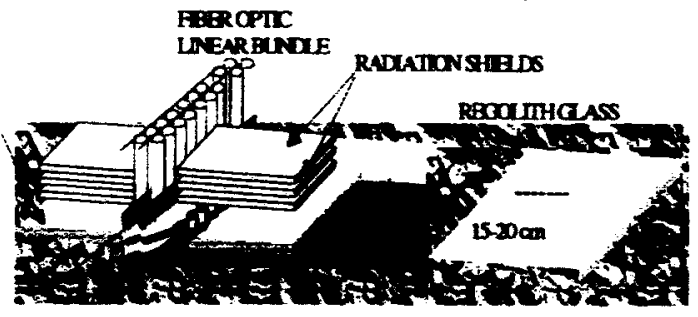

Fig. 4. Heating array to melt lunar regolith

The greatest thermal need is for regolith melting, which from requires approximately $50-60 \mathrm{~W} / \mathrm{cm}^{2}$ to process. The basic rover design was derived from a proven design of the Mars rover. It was calculated that the rover would need approximately $200 \mathrm{~W}$ of electric power to move through sand at about $2-3 \mathrm{~km} / \mathrm{mr}$. This would be used when the rover is positioning itself to the selected site. When depositing solar cells, the rover would be moving forward at a very slow pace. approximately $1 \mathrm{~cm} / \mathrm{min}$. This would produce about $180 \mathrm{~kW}$ per year. The power requirement at the time of deposition will be for positioning, sweeping or routing of fiber optics, alignment of solar array and concentrations, temperature measurement, height over surface measurement, communications, elc. A solar panel of approximately $1 \mathrm{~m}^{2}$ will be needed to provide this electrical power. The solar cell itself will about $10 \mathrm{~cm}$ long by $10 \mathrm{~cm}$ wide. The rover width will need to accommodate the width of the solar cell plus room for the interconnection wires and room for the rover wheels so they are not too close to the solar panels. We estimate that the width will be $60 \mathrm{~cm}$ to allow for these conditions. The length will be about $1.2 \mathrm{~m}$ to hold the solar panel. The power for melting the regolith and heat the source material will be provided by solar concentrators. Parabolic concentrators can be used to focus the solar energy and couple into fiber optic bundles. The bundles can be routed over the rover to whatever location is needed. The solar array can be split longitudinally and stacked on top of the concentrator array. Then the solar panel would open up and deploy on either side of the rover. This way the concentrator array and the solar panel would all point at the sun and the solar panel could be used as a shutter for the concentrator array in order to modulate the solar energy (Fig.5).
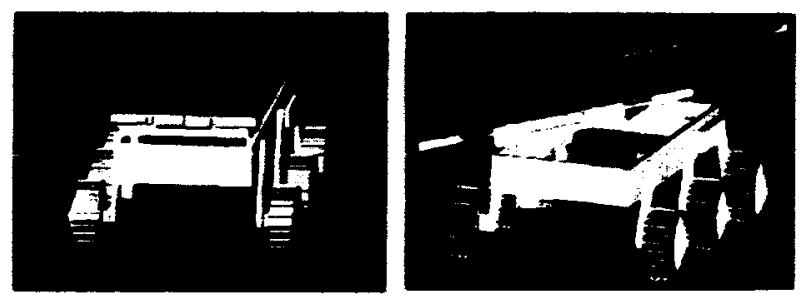

Fig. 5. Schematic representation of the rover's solar panel/ concentrator deployment mechanism.

The remaining solar collectors heat speciticallydesigned linear evaporators to sequentially deposit the bottom contact layer, the silicon layers with required dopants, the top electrode through a contact mask, the cell interconnects; and the application of the antireflection coating. Individual solar cells will connected in series and parallel by thin fitm interconnects. The paver maneuvers over the lunar surface and continuously lays down solar cells on the landscape. e.g. a -24V, 2 A array element requiring $-100 \mathrm{~g}$ of raw material (evaporants), and take about 1012 hours to fabricate. Interconnections between arrays and the power distribution system will be implemented with thick film metallic iron flat wires deposited by the Paver on the perimeters of the solar cells as part of the cell deposition process

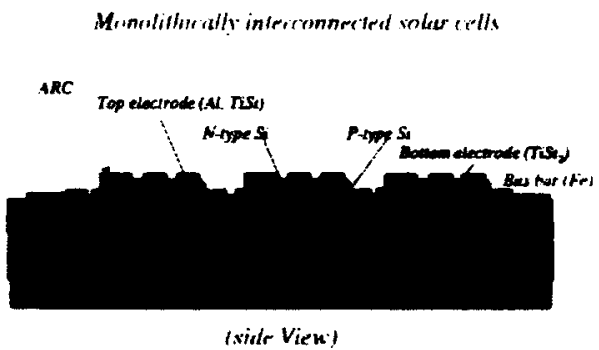

Figure 6. Schematic representation of a Si solar cell grid deposited on lunar surface

\section{Extraction of metals from lunar ore}

Although the Moon has an abundance of silicon. the element is always found in combination with other 
elements. The concept of mineral beneficiation has been an enduring paradigm in terrestrial extractive metallurgy for economic reasons. The viability of that approach to concentrating metal is questioned here for a lunar technology demonstration during which energy is at a premium. To eliminate the need for beneficiation prior to processing and to minimize the import of consumable reagents from Earth, one could use the known [3] technology of molten oxide electrolysis (MOE) to produce electronic grade silicon and iron from complex mineral feedstock to supply the solar cell paver system. Electrolytic processing has the advantage of selectivity of reaction in the presence of a multicomponent feed. Products from lunar regolith follow sequentially in decreasing free energy of oxide formation at $1500^{\circ} \mathrm{C}$; iron, silicon, titanium, aluminum, magnesium, and calcium. The proposed extraction system could consist of two reactors-the extractor and the refiner. In the exdractor, regolith is electrolytically decomposed into a primary iron-silicon alloy and oxygen gas. In the refiner, the ferrosilicon is electrolytically separated into solar 'cell' grade silicon and iron (e.g. suitable for electrical interconnects). MOE offers uncommon versatility in its insensitivity to feedstock composition. While purity levels of about $0.1 \%$ are acceptable for most elemental metals such as $\mathrm{Al}$. Fe etc... To yield a good photovoltaic material the purity of Si has to be controlled at the level of PPM. It is worth noting that we have previously shown that during the evaporation $\mathrm{Si}$ undergoes and additional vacuum purification (removal of volatile species) e.g. a $4 \mathrm{~N}$ purity Si extracted from the regolith once deposited provides a high purity p-doped Si ( $N$ doped at 10-50 PPM) [2]

\section{Cost Ansysis}

A cost model (using NAFCOM) was constructed to examine the cost-effectiveness of fabricating solar cells on the Moon using lunar resources. The cost is to be compared to transporting terrestrially fabricated arrays to the Moon of the same power. The cost analysis calculation was performed for 4 different scenarios of power generation on the Moon. The first scenario involves the fabrication of $180 \mathrm{~kW}$ per year for three years resulting in a total of $540 \mathrm{~kW}$. The second scenario again used $180 \mathrm{~kW}$ per year installed but for 10 years of installation for a total of $1,800 \mathrm{~kW}$. The third scenario allowed for a more intense fabrication period where $1 \mathrm{MW}$ is produced each year (using multiple rovers) for 10 years for a total of $10 \mathrm{~mW}$ and the fourth scenario is increased production to $1 \mathrm{GW}$ per year for 10 years for a total of $10 \mathrm{GW}$. Each scenario produces power for 10 years. The cost is calculated per $\mathrm{kW}$ and for per $\mathbf{K W}$-hr and compared to the cost of pretabricated arrays that are transported to the Moon. Estimates of development costs were made using the NAFCOM model for cost per $\mathrm{kg}$. The total mass to be transported was estimated by breaking the system down into sub components. For the model, the system would use a system to refine the regolith, a utility rover to transport refined material to the deposition rover and a rover to do the solar cell fabrication.

\begin{tabular}{|r|r|r|}
\hline $\begin{array}{c}\text { Lunar Power } \\
\text { need }\end{array}$ & $\begin{array}{c}\text { Si production } \\
\text { on Moon (SW) }\end{array}$ & $\begin{array}{r}\text { PV raw material } \\
\text { from Earth(SW) }\end{array}$ \\
\hline $0.54 \mathrm{MW}$ & 1,322 & 629 \\
\hline $1.8 \mathrm{MW}$ & 508 & 237 \\
\hline $10 \mathrm{MW}$ & 341 & 164 \\
\hline $10 \mathrm{GW}$ & 14 & 32 \\
\hline
\end{tabular}

Table 1. Per unit cost (\$ per installed watt) of lunar solar power. Substrates and metals are directly produced on the moon : in the first scenario high purity $\mathrm{Si}$ is produced from the lunar ore, in the second scenario solar cells are still produced on the moon but the high purity semiconductor is brought from earth.

Considering a transportation cost of $\$ 200,000 / \mathrm{kg}$ [4]. the model indicates that the fabrication of solar cells on the moon (when even compared to uitra fightweight solar cells $0.5-1 \mathrm{~kW} / \mathrm{Kg}$ ) becomes cost effective in the MW range. However the production of high purity PV material ( $\mathrm{Si}$ in this case) becomes a preferred option only for large power requirements in the G-watts range.

\section{SUMMARY}

Results on the fabrication and properties of lunar glass substrates, evaporated lunar regolith thin films (anti-reflect coatings and insulators). and preliminary attempts in the tabrication of thin fitm (silicon/l-Vi) photovoltaic materials on lunar regolith substrates wore discussed. A conceptual design for a solar powered robotic rover capable of fabricating solar cells directy on the lunar surface is provided. Technical challenges in the development of such facility and strategies to alleviate perceived difficulties were discussed. Finally. preliminary cost benefit ratio indicated the potential of the technology for a large-scale deployment of PV power on the moon.

\section{AKNOWLEDGWENTS}

This work was partially supported by NASA Cross Enterprise Technology Development Program.

\section{REFERENCES}

[1] A. Cohen "Report of the 90-Day Study on Human Exploration of the Moon and Mars," NASA, Nov.1989.

[2] A. Freundlich, T. Kubricht, and A. Ignatiev: "Lunar Regolith Thin Films: Vacuum Evaporation and Properties," AIP Conf. Proc., Vol. 420, (1998) p. 660

[3]. Sadoway, D.R.: "Electrolytic Production of Metals Using Consumable Anodes," U.S. Patent No. 5,185,068, February 9, 1993.

[4] Duke, M.B.; Blair, B.; and J. Diaz: "Lunar Resource Utilization," Advanced Space Research, Vol. 31(2002) p. 2413. 